\title{
INTELLECTUAL IMPAIRMENT IN CHILDREN WITH LOCALIZED POST-INFANTILE CEREBRAL LESIONS
}

\author{
BY \\ JOHN McFIE \\ From the National Hospital, Queen Square, London
}

In the past decade, a considerable amount of evidence has been published demonstrating the association in adult patients between specific intellectual losses and lesions in different parts of the cerebrum. In children, however, well-localized cerebral lesions are relatively rare, and there are few studies of associated intellectual changes; yet an understanding of the relationship of impairment to cerebral damage is of importance both from a theoretical point of view and to enable a full clinical assessment, particularly of prognosis concerning mental development, to be made.

Comprehensive data on patterns of impairment of adult patients on the Wechsler intelligence scales and other intellectual tests have been presented by McFie and Piercy (1952), by Reitan (1959), and by McFie (1960a): detailed studies of the impairment associated with lesions of the frontal lobes have been published by Rylander (1939); of the temporal lobes by Milner $(1954,1958)$ and by Bingley (1958); and of subcortical nuclei by Riklan, Diller, Weiner, and Cooper (1960) and by McFie (1960b). The intellectual functions typically impaired by lesions in different anatomical lobes are summarized in Table I: perhaps the most significant conclusion which may be drawn from this is that lesions of the left hemisphere are typically associated with verbal impairment, and lesions of the right with losses on performance tests. This has also been emphasized by other authors (Morrow and Mark, 1955;

\section{TABLE I}

RESULTS OF TESTS SHOWING SIGNIFICANT MEAN IMPAIRMENT ASSOCIATED WITH LOCALIZED LESIONS (MCFIE, 1960a)

\begin{tabular}{l|l}
\hline \multicolumn{1}{c|}{ Site of Lesion } & \multicolumn{1}{c}{ Tests Showing Impairment } \\
\hline Left frontal & $\begin{array}{l}\text { Digit span } \\
\text { Left temporal }\end{array}$ \\
$\begin{array}{l}\text { Digit span, similarities } \\
\text { Right frontal } \\
\text { Right temporal } \\
\text { Right parietal }\end{array}$ & $\begin{array}{l}\text { Pigit span, arithmetic, block designs } \\
\text { Picture arrangement, memory for designs } \\
\text { Picture arrangement, memory for designs } \\
\text { designs }\end{array}$ \\
\hline
\end{tabular}

Heilbrun, 1956) and lends no support to the frequent practice of assessing organic intellectual impairment in terms of the 'verbal minus performance' formula.

In children, there is evidence that there is a striking difference between the intellectual effects of localized cerebral lesions sustained in the first year of life and in subsequent years. Following the report by Krynauw (1950) that removal of the left hemisphere in infantile hemiplegics resulted in no speech disturbance, a series of studies of patients following hemispherectomy (Cairns and Davidson, 1951; Gardner, Karnosh, McClure, and Gardner, 1955) makes it clear that in cases of injury to either hemisphere at birth or infancy the intellectual functions of both hemispheres are mediated by the undamaged hemisphere alone. McFie (1961a) pointed out that there appeared to be a limit to the intellectual capacity of such patients, the mean I.Q.s of his own series and of reported cases being in the region of 60 points; and also that these patients tended to have lower 'verbal' than 'performance' scores, regardless of which hemisphere had been injured.

In cases of unilateral injury after one year of age, however, the impairment appears to approximate to the conventional adult pattern of verbal deficit with left, and performance deficit with right, hemisphere lesions. This is particularly clear from reports of aphasic children: Karlin (1954) stated that on intelligence tests they show 'a scattered picture, being strikingly backward in verbal tests and showing normal responses in performance tests'. Bryan and Brown (1957), in a study of 40 supposedly 'organic' subjects, stated that 'in contrast to the commonly reported organic pattern, a number of adolescents in the present study had superior performance scores', a conclusion illustrated by a typical case of severe left hemisphere injury at the age of 6 years. These authors also claimed that 'there was a trend for lower full scale I.Q.s to be associated with early brain injury'. 
Their subjects whose impairment was present at birth had a mean I.Q. of 62 , and in those having infantile injuries it was 66: no other clinical evidence concerning these patients was presented, but the mean figures agree well with other reports. The mean I.Q.s of their subjects injured between 3 and 10 years of age was 71 , and of those injured between 10 and 20 years was 85 .

In spite of the number of publications on "cerebral palsy', reports of psychological test results have not generally been concerned with localization or age of onset of the lesion, and results have not been analysed in detail. Thus the extensive account by Taylor (1959) does not attempt to establish any patterns of results for groups, and presents only a few illustrative cases, while Denhoff and Robinault (1960) emphasize the clinical value of Wechsler's children's scale, but repeat the assertion that impairment is likely to be reflected by 'verbal higher than performance' scores. Jewell and Wursten (1952) analysed the results of 166 'cerebral palsied' children tested on the Terman-Merrill scale and 41 on the Wechsler-Bellevue scales, and found that on both scales 'none of these children had vocabulary as his weakest point': this agrees with evidence from testing adults that the vocabulary score is relatively insensitive to cerebral damage. Moreover, the authors found that their subjects were 'twice as likely to have low scores in memory as they were to have high scores'. This applied to both verbal and visual memory, a point of similarity with adult patients. On the Bellevue scale, as many subjects had high verbal I.Q.s as had high performance I.Q.s.

There is suggestive evidence then that the patterns of intellectual impairment in children with postinfantile cerebral injuries approximates to those found in adults. However, just as the symptoms of aphasia may be less obvious in children than in adults (Guttmann, 1942), so the patterns of intellectual impairment may be less precise.

\section{Clinical Material}

The patients were all those tested during the last 10 years by the psychologists at the National Hospitals, Queen Square, and Maida Vale, who fulfilled the following criteria: they were between the ages of 5 and 15 years; a unilateral pathological process in the cerebrum began after 1 year of age; the location of the cerebral lesion had been verified either at necropsy or operation, or by air-encephalography, or (in the case of electrical foci with no other abnormal finding) by persistence of a focus at repeated E.E.G. examinations over a period of at least one year. The only patients omitted were those reported as unable or unwilling to cooperate in testing, or those in whom testing was inadequate: there may therefore be a bias towards omission of the more grossly defective or disturbed children. The age at testing and diagnosis of the $\mathbf{4 0}$ patients is shown in Table II.

\section{Test Results}

The patients were tested either on the TermanMerrill (1937) and Kohs' (1923) block tests, or on one of the Wechsler scales (Bellevue-Wechsler, 1944 , Wechsler, 1949). Five patients fall into both groups, and their results are included with those of both groups.

Intelligence Quotients.-Table III shows the numbers and mean I.Q.s of the patients (on theo Terman-Merrill or Wechsler scales) grouped accord? ing to site of lesion. For the five patients tested ono

TABLE III

NUMBERS AND MEAN I.Q.S OF PATIENTS

\begin{tabular}{l|c|c}
\hline \multicolumn{1}{c|}{ Site of Lesion } & Number of Patients & Mean I.Q. \\
\hline Left frontal & 4 & $89 \cdot 3$ \\
Left temporal & 11 & $91 \cdot 3$ \\
Left parietal & 12 & $73 \cdot 3$ \\
Right frontal & 2 & $64 \cdot 0$ \\
Right temporal & 6 & $88 \cdot 8$ \\
Right parietal & 5 & $88 \cdot 6$ \\
\hline
\end{tabular}

TABLE II

AGE AT TESTING AND NATURE OF CEREBRAL LESION OF PATIENTS

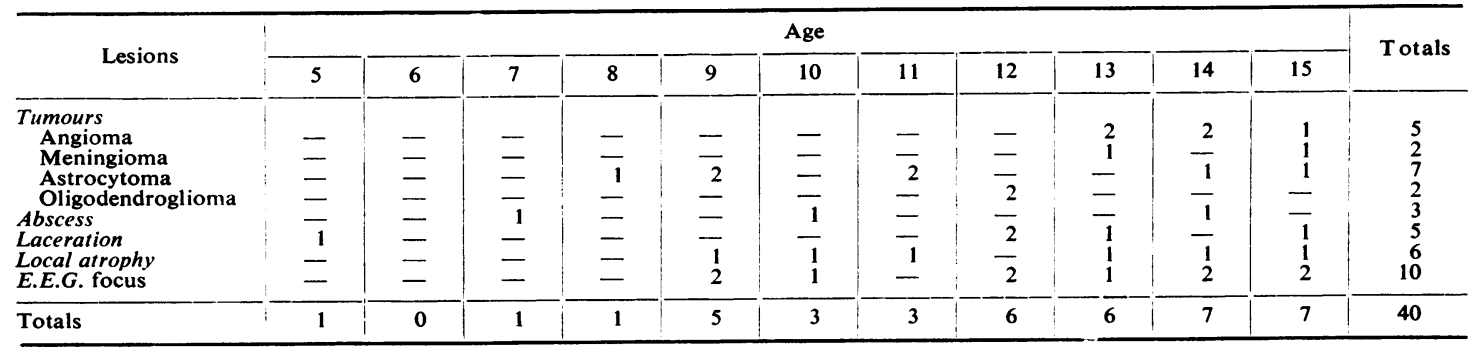


both tests, only the Wechsler I.Q.s are used. Oneway analysis of variance shows that the variation within groups is greater than that between groups, and therefore that the variation attributable to the site of the lesion is not significant.

In view of the claim of Bryan and Brown (1957) that lower I.Q.s were associated with earlier injuries, the patients' I.Q.s were also averaged for groups according to the age of onset of the lesion (Table IV).

\section{TABLE IV}

MEAN I.Q.S OF PATIENTS BY AGE OF ONSET OF LESION

\begin{tabular}{c|c|c}
\hline Ages (years) & Number & Mean I.Q. \\
\cline { 2 - 3 } $1-4$ & 5 & $88 \cdot 8$ \\
5.9 & 15 & $106 \cdot 0$ \\
$10-15$ & 20 & $82 \cdot 7$ \\
\hline
\end{tabular}

The ages at which lacerations, or accidents resulting in atrophic processes, occurred could be determined from the case histories: in cases of tumour and E.E.G. focus, the patients were classified as accurately as possible according to the age of appearance of the first relevant symptom. It will be seen from Table IV that there is no suggestion of a trend associating full I.Q. with age at injury.

Verbal/Performance Differences.-Both the Terman-Merrill and the Kohs' block scales yield only a single measure, designated in both cases as the I.Q. However, the content of the former test is largely verbal, while that of the latter appears to be entirely non-verbal. For the patients who did these tests, a comparison between verbal and performance levels may be made by comparing the two I.Q.s. Table $\mathrm{V}$ shows the numbers with left and with right hemisphere lesions whose I.Q.s were lower on the verbal than on the performance tests. While the

TABLE $\mathbf{V}$

ASSOCIATION BETWEEN TYPE OF DEFICIT AND SIDE OF LESION

\begin{tabular}{l|c|c}
\hline \multirow{2}{*}{ Lower I.Q. on } & \multicolumn{2}{|c}{ Hemisphere Involved } \\
\cline { 2 - 3 } & Left & Right \\
\hline Verbal (T-M) & 5 & 3 \\
Performance (K) & 2 & 5 \\
\hline
\end{tabular}

figures do not reach statistical significance $\left(\chi^{2}=1 \cdot 6\right)$ it will be seen that there is a tendency for verbal deficit to be associated with left, and performance deficit with right, hemisphere lesions.

Wechsler Subtests-For each subtest of the Wechsler scales, the difference has been calculated between each patient's score and the normal mean at the patient's age. For Bellevue weighted scores, the age means are stated by Wechsler $(1944$, p. 222$)$ : for W.I.S.C. scaled scores the mean at each age is 10 points (Wechsler, 1949). Table VI shows the mean of the 'difference scores' of the patients with lesions in the left and in the right hemisphere. In

\section{TABLE VI}

MEANS OF DIFFERENCES BETWEEN PATIENTS' SCALED SCORES AND AGE MEANS ON WECHSLER SUBTESTS

\begin{tabular}{|c|c|c|c|c|}
\hline \multirow{3}{*}{ Subtest } & \multicolumn{4}{|c|}{ Hemisphere Involved } \\
\hline & \multicolumn{2}{|c|}{ Left } & \multicolumn{2}{|c|}{ Right } \\
\hline & No. & $\begin{array}{l}\text { Mean } \\
\text { Score }\end{array}$ & No. & $\begin{array}{l}\text { Mean } \\
\text { Score }\end{array}$ \\
\hline $\begin{array}{l}\text { Digit span } \\
\text { Arithmetic } \\
\text { Similarities } \\
\text { Vocabulary } \\
\text { Picture completion } \\
\text { Picture arrangement } \\
\text { Block designs } \\
\text { Digit symbol }\end{array}$ & $\begin{array}{l}20 \\
21 \\
22 \\
22 \\
21 \\
12 \\
22 \\
16\end{array}$ & $\begin{array}{r}-2.9 \\
-1.4 \\
-0.9 \\
-1 \cdot 8 \\
0.7 \\
-1 \cdot 3 \\
0.2 \\
-2.0\end{array}$ & $\begin{array}{l}8 \\
9 \\
8 \\
8 \\
9 \\
6 \\
6 \\
8\end{array}$ & $\begin{array}{r}-0.9 \\
-1 \cdot 0 \\
0 \cdot 4 \\
-2 \cdot 0 \\
0 \cdot 1 \\
-3 \cdot 3 \\
-0.9 \\
-4 \cdot 7\end{array}$ \\
\hline
\end{tabular}

spite of the considerable differences between some of the means for left- and right-sided lesions (e.g., digit span, picture arrangement, and digit symbol tests) none of these is statistically significant, owing to the wide range of variation in individual scores. Nevertheless, it is interesting to compare the direction of differences with those found in adult patients (Table I): with digit span and similarities tests the directions are similar, showing a tendency toward greater deficit with lesions in the left hemisphere; with picture arrangement and block design tests likewise, lower scores being associated with right hemisphere lesions; and also with picture completion, in which there is no mean deficit with lesions in either hemisphere. The greater deficit on the digit symbol test with right hemisphere lesions was not found in adults; and the considerable mean deficit on the vocabulary test with lesions in either hemisphere is altogether different from the findings in adults, who showed no mean deficit on this test with lesions in any location.

Memory for Designs.-This test occurs in the Terman-Merrill scale (1937) and was also given as an isolated test to patients who did the Wechsler scales. The scoring followed the Terman-Merrill criteria, but one and two points were awarded in place of a half and one. The mean scores of patients grouped by site of lesion are shown in Table VII. Not only is the difference between the mean scores of those patients with left and with right hemisphere lesions highly significant $(t=3 \cdot 5$. $P<0.01)$, but oneway analysis of variance of the six lesions groups 
TABLE VII

MEAN SCORES ON MEMORY FOR DESIGNS

\begin{tabular}{l|c|c}
\hline Site of Lesion & No. & Mean Score \\
\hline Left frontal & 3 & $3 \cdot 3$ \\
Left temporal & 7 & $3 \cdot 4$ \\
Left parietal & 7 & $2 \cdot 7$ \\
Right frontal & 1 & $2 \cdot 0$ \\
Right temporal & 3 & $3 \cdot 0$ \\
Right parietal & 5 & $1 \cdot 8$ \\
\hline
\end{tabular}

yields a significant variance ratio $(F=3.97, \mathrm{P}<0.05)$, indicating an association between the site of lesion and the extent of deficit on this test. These results are similar to those of adult patients, including the finding of greater deficit in the Right Parietal group.

Clinical Disabilities.-Five of the patients with left hemisphere lesions, and none with right hemisphere lesions, were frankly dysphasic: two showed mixed dysphasias, in one the disability was exclusively nominal, and in two it was of the type described by Guttmann (1942), characterized by reduction of speech. Two patients with right-sided lesions, and none with left-sided lesions, showed a degree of disability in constructional and drawing tests that amounted to spatial agnosia. These associations are similar to those found in adults.

Handedness.-Four patients were left-handed, i.e., preferred to use the left hand for writing and other unimanual tasks: three with right hemisphere lesions and one with a left hemisphere lesion. The pattern of impairment, i.e., deficit on verbal or performance tests, of each of these patients was similar to those of the others, that is, to the majority of the right-handed patients with lesions in the same situations. This absence of difference between patterns of impairment of the majority of right- and left-handed patients is also similar to findings with adult patients.

\section{Discussion}

The test results of these children fall into two groups: those which are similar to results of testing adult patients with lesions in similar locations, and those which are dissimilar.

In the first group, the closest resemblance to the pattern of impairment usually found in adults is found with the memory for designs test: this shows not only the conventional association of impairment with right hemisphere lesions, but also of greatest deficit with right parietal lesions. There is also a similarity between the children and adult patients in the absence of impairment on the picture completion test. It may therefore be postulated that, within the age range of the patients tested (from 9 to 15 years) the cerebral organization mediating these abilities has become established in adult form. It must be emphasized, however, that these data refer only to children with an English cultural background: in children of other cultures, in whom non-verbal ability is frequently not so advanced (cf. McFie, 1961b), this pattern of impairment might not be found.

A resemblance, though of lesser degree, to adult patterns of impairment is shown in the associations between hemisphere injured and deficit on the digit span, similarities, picture arrangement, and block design tests in the Wechsler scales, and on verbal and performance levels on the Terman-Merrill and क Kohs' blocks scales. The failure of any of the dif- $\vec{\theta}$ ferences on these tests to reach statistical significance may be ascribed in part to the relatively small numbers of subjects; but, had they been adults at the time of acquiring lesions, it may confidently be stated that there would have been significant differences, even with these numbers, between groups with right and left hemisphere lesions. It appears that in these children the pattern of cerebras os organization mediating these abilities approx mates to, but is not yet established in, adu? form.

Differences from the pattern of deficit normal found in adult patients are shown in the results of vocabulary and digit symbol tests. The greate deficit on the latter test in the group with rige hemisphere lesions may suggest a greater implication of 'right hemisphere functions' in its performance in this age group; but this would have to be confirmed on a larger series of patients. The deficits on vocabulary with lesions in either hemisphere are in agreement with the findings of Hebb (1942), and might suggest that more widespread cerebral regions are concerned in the development of this function in the child than in its later use by the adult. A similar proposal, though with special reference to the prefrontal lobes, has been made by Russell (1959); ' . . . the prefrontal lobes play a specially important part in mental development during the years of learning ...'

The data concerning the intelligence levels of the patients do not demonstrate any overall differences between groups: they serve, perhaps, to emphasize $ᄋ$ the paucity of information provided by the single I.Q. The numbers in this group of patients are $\frac{\text { I }}{2}$ insufficient, but it would be particularly valuable if a $>$ study were undertaken of the patterns of deficit on these tests associated with different ages at testing $N$ and also with different ages at which the lesion was acquired. 


\section{Summary}

Intelligence test results of 40 children with localized cerebral lesions, acquired after the first year of life, are analysed. The association of deficit on the tests with the presence of lesions in certain locations, resembling to a greater or lesser degree the association commonly found in adult patients, is found with performance tests, memory for designs, block designs, picture arrangement (right hemisphere lesions); with verbal tests, digit span, similarities (left hemisphere lesions); and with picture completion (little deficit). It is suggested that the degree to which the pattern of impairment on a test resembles that found in adults reflects the extent of approximation to adult cerebral organization mediating the function.

I am indebted to members of the staff of the National Hospitals, Queen Square and Maida Vale, for permission to refer to results of patients under their care, and to my colleagues, and particularly Miss $M$. Durward, lately psychologist, Maida Vale Hospital, for many of the test results. I am also grateful to Drs. Alick Elithorn and R. T. C. Pratt for their encouragement and interest in this study, and to Dr. G. Ettlinger for his criticism of the draft manuscript.

\section{REFERENCES}

Bingley, T. (1958). Mental Symptoms in Temporal Lobe Epilepsy and Temporal Lobe Gliomas. Acta psychiat. (Kbh.), 33, Suppl. 120.

Bryan, G. E., and Brown, M. H. (1957). J. nerv. ment. Dis., 125, 69. Cairns, H., and Davidson, M. A. (1951). Lancet, 2, 411.

Denhoff, E., and Robinault, I. R. (1960). Cerebral Palsy and Related Disorders. McGraw-Hill, New York.

Gardner, W. J., Karnosh, L. J., McClure, C. C., and Gardner, A. K. (1955). Brain, 78, 487

Guttmann, E. (1942), Ibid, 65, 205

Hebb, D. O. (1942). Proc. Amer. Philos. Soc., 85, 275.

Heilbrun, A. B. (1956). J. comp. physiol. Psychol., 49, 10.

Jewell, B. T., and Wursten, H. (1952). Amer. J. ment. Defic., 56, 630.

Karlin, I. W. (1954). Amer. J. Dis. Child., 87, 752.

Kohs, S. C. (1923). Intelligence Measurement. Macmillan, New York.

Krynauw, R. A. (1950). J. Neurol. Neurosurg. Psychiat., 13, 243.

McFie, J. (1960a). J. nerv. ment. Dis., 131, 383.

(1960b). J. ment. Sci., 106, 1512.

(1961a). J. Neurol. Neurosurg. Psychiat., 24, 240.

(1961b). Brit. J. Psychol., In press.

, and Piercy, M. F. (1952).' Brain, 75, 292.

Milner, B. (1954). Psychol. Bull., 51, 42. (1958). Res. Publ. Ass. nerv. ment. Dis., 36, 244.

Morrow, R. S., and Mark, J. C. (1955). J. cons. Psychol., 19, 283.

Reitan, R. M. (1959). The Effect of Brain Lesions on Adaptive Abilities in Human Beings. Indiana University, Indiana.

Riklan, M., Diller, L., Weiner, H., and Cooper, I. S. (1960). Arch. gen. Psychiat., 2, 22.

Russell, W. Ritchie (1959). Brain, Memory, Learning. Clarendon Press, Oxford.

Rylander, G. (1939). Personality Changes after Operations on the Frontal Lobes, E. Munksgaard, Copenhagen.

Taylor, E. M. (1959). Psychological Appraisal of Children with Cerebral Defects. Harvard University Press.

Terman, L. M., and Merrill, M. A. (1937). Measuring Intelligence. Harrap, London.

Wechsler, D. (1944). The Measurement of Adult Intelligence, 3rd ed. Williams and Wilkins, Baltimore.

- (1949). Wechsler Intelligence Scale for Children. Psychological Corporation, New York. 